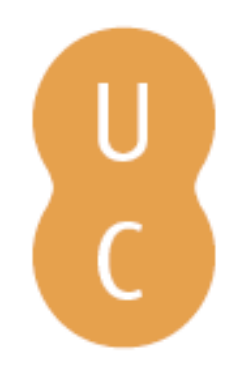

\title{
pombalina
}

\section{La relación del hombre con la naturaleza y el medio ambiente}

\author{
Autor(es): $\quad$ Fedeli, Paolo
}

Publicado por: Associação Portuguesa de Estudos Clássicos; Imprensa da

URL

persistente: URI:http://hdl.handle.net/10316.2/31797

DOI: $\quad$ DOI:http://dx.doi.org/10.14195/978-989-721-069-3_33

Accessed : $\quad$ 26-Apr-2023 11:17:26

A navegação consulta e descarregamento dos títulos inseridos nas Bibliotecas Digitais UC Digitalis, UC Pombalina e UC Impactum, pressupõem a aceitação plena e sem reservas dos Termos e Condições de Uso destas Bibliotecas Digitais, disponíveis em https://digitalis.uc.pt/pt-pt/termos.

Conforme exposto nos referidos Termos e Condições de Uso, o descarregamento de títulos de acesso restrito requer uma licença válida de autorização devendo o utilizador aceder ao(s) documento(s) a partir de um endereço de IP da instituição detentora da supramencionada licença.

Ao utilizador é apenas permitido o descarregamento para uso pessoal, pelo que o emprego do(s) título(s) descarregado(s) para outro fim, designadamente comercial, carece de autorização do respetivo autor ou editor da obra.

Na medida em que todas as obras da UC Digitalis se encontram protegidas pelo Código do Direito de Autor e Direitos Conexos e demais legislação aplicável, toda a cópia, parcial ou total, deste documento, nos casos em que é legalmente admitida, deverá conter ou fazer-se acompanhar por este aviso.

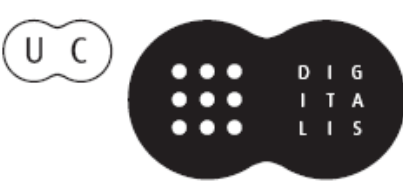




\section{Espaços e Paisagens}

\section{Antiguidade Clássica e Heranças Contemporâneas}

Vol. I Línguas e Literaturas. Grécia e Roma

Francisco de Oliveira, Cláudia Teixeira, Paula Barata Dias (coords.)

IMPRENSA DA UNIVERSIDADE DE COIMBRA 


\title{
LA RELACIÓN DEL HOMBRE CON LA NATURALEZA Y EL MEDIO AMBIENTE
}

\author{
Paolo Fedeli \\ UNIVERSIDADE DE BARI
}

\section{Résumé}

Ces pages constituent une réflexion sur l'attitude des Romains en face du monde naturel et sur leurs soucis et leurs craintes quand il s'agissait de le modifier.

El problema de la relación entre ambiente y sociedad ha constituido materia de comparación, en el trascurso de los siglos, entre posiciones antitéticas, ligadas una al concepto del dominio del ambiente físico sobre el hombre, la otra a la idea de la superioridad del hombre sobre el ambiente físico. Nos interesa aquí determinar si los antiguos han reflexionado sobre su relación con el medio ambiente y si, y hasta qué punto, la han vivido como un conflicto. Paradójicamente las tomas de posición teóricas nos son de muy escasa ayuda: sin embargo no se puede hablar de una falta de sensibilidad de los antiguos porque su error ha continuado hasta épocas recientes. Desde la antigüedad hasta almenos Montesquieu, en efecto, el problema de la relación hombre-ambiente ha sido enfrentado de manera opuesta a aquella que hoy consideramos la impostación fundamental: se ha prestado atención sólo a los condicionamientos del ambiente sobre el hombre y se ha establecido una relación directa entre ambiente, clima, recursos, de un lado, características físicas y comportamiento de las distintas poblaciones, del otro (la teoría del determinismo ambiental). No se ha prestado atención en absoluto, en cambio, a la inevitable interacción y al condicionamiento recíproco entre un pueblo y su ecosistema.

Puesto en estos términos, en la elaboración teórica y en la óptica de los pueblos dominantes, el problema tenía una conclusión descontada a priori. Para los Romanos, en efecto, no existían dudas: su superioridad era también fruto del ambiente mejor en que ellos vivían. No por casualidad en época augústea la oposición con el Oriente - tierra de antigua cultura y civilización - se expresa a través de las laudes Italiae, desde Varrón a Virgilio y a Propercio: en ellas Italia es considerada la tierra mejor en todos los aspectos, sobre todo en el climático y ambiental. En cuanto a la superioridad que les venía de las afortunadas condiciones ambientales, los Latinos no hacían sino retomar convicciones enraizadas en la mentalidad griega desde siglos. 
Que los Romanos hayan nutrido un vigilante cuidado con respecto al medio ambiente y se hayan puesto el problema de la relación entre el hombre y su 'habitat' natural es atestiguado por lo menos por un caso emblemático: el escrúpulo en relación con los predios agrícolas y la acuciosa evaluación de su ubicación antes de proceder a adquisiciones incautas.

$\mathrm{Si}$ todos los escritores de textos sobre agricultura insisten sobre la necesidad de escoger lugares salubres además que fértiles, esto depende del hecho de que existían loca pestilentia donde reinaba la malaria, o zonas dificilmente habitables como las de la Campania apestadas por las exhalaciones de las solfataras. Si se trataba de predios de extensión limitada, podían ser practicadas intervenciones de naturaleza científica para sanear ambientes agrícolas malsanos. Nos habla de esto Varrón, que opone los fundos salubres, de renta segura, a los malsanos, demostrando en el segundo caso una clara conciencia, ya del carácter negativo de la relación hombre-ambiente, ya de la necesidad de intervenciones saneadoras $(1,4,3-4)$ :

In pestilenti calamitas, quamvis in feraci agro, colonum ad fructus pervenire non patitur. Etenim ubi ratio cum orco habetur, ibi non modo fructus est incertus, sed etiam colentium vita. Quare ubi salubritas non est, cultura non aliud est atque alea domini vitae ac rei familiaris. $\mathrm{Nec}$ haec non deminuitur scientia. Ita enim salubritas, quae ducitur e caelo ac terra, non est in nostra potestate, sed in naturae, ut tamen multum sit in nobis, quo graviora quae sunt ea diligentia leviora facere possimus. Etenim si propter terram aut aquam odore, quem aliquo loco eructat, pestilentior est fundus, aut propter caeli regionem ager calidior sit, aut ventus non bonus flet, haec vitia emendari solent domini scientia ac sumptu, quod permagni interest ubi sint positae villae, quantae sint, quo spectent porticibus, ostiis ac fenestris.

Notamos en este contexto una vigilante preocupación no solamente por la elección del ambiente ideal, sino también por la salud de los cultivadores. Si por un lado se reconoce que la salubridad de un lugar no depende del hombre sino de la naturaleza, por el otro se reconocen al hombre márgenes notables de intervención para atenuar los peligros gracias a la acción de su scientia (nec haec non deminuitur scientia). Naturaleza del suelo, sabor del agua, exhalaciones, clima, exposición a vientos dañinos, son todos elementos a los cuales, según Varron, se puede hacer frente sirviéndose de los recursos de la técnica y, por cierto, con los gastos adecuados (haec vitia emendari solent domini scientia ac sumptu).

El pasaje de Varrón pone ante nuestros ojos una realidad agrícola en que la intervención del hombre aparece limitada a su propio predio. La suya, sin embargo, es una confesión de fe en la ciencia y en las posibilidades de intervención del hombre sobre el ambiente natural desfavorable, que merece ser subrayada: no debía ser fácil, en efecto, traducir el pensamiento en acción eficaz, sobre todo si subentraban escrúpulos de carácter religioso. Intervenciones de más ampla envergadura, en efecto, eran practicadas raramente, no sólo por las dificultades que presentaban, sino y sobre todo por un religioso sentimiento de respeto en relación con el orden natural. En la concepción de los antiguos, en realidad, toda intervención que modificara lo que la naturaleza había sabiamente dispuesto, 
era considerada sacrílega y exponía al riesgo de puniciones divinas. No estamos, por tanto, en presencia de un conflicto entre modernidad e innovación, en que lo nuevo fatiga a abrirse camino por incapacidad de comprenderlo o por resistencia a ponerlo en acto; se trata más bien de una exigencia - del todo ignota a nosotros modernos - de respeto religioso del ambiente natural que, en cuanto tal, no debe ser violado o alterado. Cada intervención en la naturaleza exigirá pues una adecuada purificación.

Hoy el problema de la explotación de los recursos naturales se pone siempre más dramático: hay clara conciencia de que - con excepción de la energía solar - todos los bienes naturales tradicionalmente considerados inagotables están gravemente comprometidos por un uso irracional y poco juicioso por parte de la civilización industrial. A los antiguos, evidentemente, el 'habitat' ecológico se presentaba en muy otras condiciones: este estado de cosas justifica la presencia del mito de la inagotabilidad de los recursos naturales en la producción literaria antigua. Esta concepción está ya expresada, a propósito de la explotación de los recursos del subsuelo, en el De vectigalibus de Jenofonte: en más de un pasaje $(1,4 ; 4,2-3$ y $4-5)$ es subrayada la inagotabilidad, en Ática, del mármol pentélico, de las minas de platas del Laurion, de todo lo que garantizaba a Atenas su predominio. Jenofonte asegura que - no obstante la continua actividad de extracción de la plata del Laurion - las venas no se han reducido en el tiempo.

Una bien diversa conciencia del problema y una clara alusión a la posibilidad de un agotamiento de los recursos del subsuelo, será expresada por Plinio el Viejo con palabras que no parecen dictadas por un fin exclusivamente moralístico (Nat. 33,2-3):

\begin{abstract}
imus in viscera et in sede manium opes quaerimus, tamquam parum benigna fertilique qua calcatur. Et inter haec minimum remediorum gratia scrutamur, quoto enim cuique fodiendi causa medicina est? Quamquam et hoc summa sui parte tribuit ut fruges, larga facilisque in omnibus, quaecumque prosunt. Illa nos peremunt, illa nos ad inferos agunt, quae occultavit atque demersit, illa, quae non nascuntur repente, ut mens ad inane evolans reputet, quae deinde futura sit finis omnibus saeculis exhauriendi eam, quo usque penetratura avaritia. Quam innocens, quam beata, immo vero etiam delicata esset vita, si nibil aliunde quam supra terras concupisceret, breviterque, nisi quod secum est!
\end{abstract}

Al comienzo es expresado el temor del sacrilegio: introducirse en las entrañas de la tierra para buscar metales preciosos equivale a entrar en contacto con el Hades. Pero en la afirmación inicial hay algo más: la actividad minera es contrapuesta a la agrícola (tamquam parum benigna fertilique qua calcatur). Las riquezas ocultas en la profundidad de la tierra son consideradas como la verdadera ruina del hombre, que no titubea en bajar a los infiernos. La mente humana, con su imaginación, puede prever al día en que, a fuerza de excavar, la tierra será completamente vaciada (quae deinde futura sit finis omnibus saeculis exhauriendi eam). Estas palabras nos hacen divisar en él, más allá del discurso 
convencional contra la codicia, la intuición del previsible agotamiento de los recursos naturales por culpa de la actividad humana. También en este caso se advierte, de todos modos, el eco de antiquísimas preocupaciones religiosas: excavar la tierra para extraer aquello que está oculto en sus entrañas constituye, en efecto, una grave violación de la naturaleza.

El agua está asociada, más que cualquier otro elemento de la naturaleza, a una serie de valores religiosos, tales que pueden garantizar un reverente respeto y una solida protección a las fuentes y a los ríos, desde lo más pequeños hasta lo más grandes. Por causa del carácter sacral de las aguas, cualquier intervención destinada a regularlas o a modificarlas fue emprendida sólo en casos de extrema necesidad. Tácito nos atestigua que el mismo senado, en el año 15 después de Cristo, rehusó emprender obras aptas para evitar las continuas inundaciones del Tíber, precisamente por temores de carácter religioso (Ann. 1,79):

Actum deinde in senatu ab Arruntio et Ateio an ob moderandas Tiberis exundationes verterentur flumina et lacus, per quos augescit; auditaeque municipiorum et coloniarum legationes, orantibus Florentinis ne Clanis solito alveo demotus in amnem Arnum transferretur idque ipsis perniciem adferret. Congruentia his Interamnates disseruere: pessum ituros fecundissimos Italiae campos, si amnis Nar (id enim parabatur) in rivos diductus superstagnavisset. Nec Reatini silebant, Velinum lacum, qua in Narem effunditur, obstrui recusantes, quippe in adiacentia erupturum; optume rebus mortalium consuluisse naturam, quae sua ora fluminibus, suos cursus utque originem, ita finis dederit; spectandas etiam religiones sociorum, qui sacra et lucos et aras patriis amnibus dicaverint: quin ipsum Tiberim nolle prorsus accolis fuviis orbatum minore gloria fluere. Seu preces coloniarum seu difficultas operum sive superstitio valuit, ut in sententiam Pisonis concederetur, qui nil mutandum censuerat.

Hay un problema por resolver con urgencia (el desequilibrio idrogeológico que producen las continuas inundaciones del Tíber); las causas verdaderas, que consisten en la frenética actividad de tala, no vienen individuadas. Se queda anclados al acontecimiento que hay que eliminar (las inundaciones del Tíber) y se sugiere una serie de propuestas en las cuales los opositores a toda modificación ven la fuente de ulteriores desequilibrios. Las soluciones que deberían ser adoptadas prevén intervenciones radicales de notable envergadura (desviar el curso de los ríos y de los lagos que alimentan el Tíber: el Chiana debería confluir en el Arno, el Nera debería ser separado en muchos canales, mientras que un dique sería destinado a impedir al lago Velino desembocar en el Nera). Adversos al proyecto son los representantes de algunos municipios y colonias, por sus particolares temores: los Florentinos temen una inundación del Arno engrosado por las aguas del río Chiana, los habitantes de Terni temen que sus fértiles campos, inundados por el Nera, se transformen en pantanos cenagosos, los Reatinos temen que el lago Velino, no logrando ya contener las aguas, inunde sus tierras. A tales motivos, más que concretos, se siente sin embargo la necesidad de agregar otros y más decisivos argumentos: el primero es de carácter naturalístico y repropone la prohibición de transtornar lo que 
ha sido fijado por la naturaleza, que no puede haberse equivocado en asignar a los ríos un manantial, un curso y desembocaduras precisas. El segundo es de naturaleza religiosa: es necesario respetar los cultos que los aliados habían dedicado a sus ríos. Como tercero y decisivo argumento se aduce la majestad del Tíber: ¿Cómo habría acogido el divus amnis la decisión de privarlo de sus afluentes? Ciertamente se habría ofendido por el disminuido prestigio. En conclusión, no se operó ninguna intervención y el Tíber continuó inundando periódicamente Roma. Tácito se limita a resumir los obstáculos mayores del proyecto, sin dar su interpretación: la oposición de los representantes de los municipios y de las colonias, la dificultad de la obra, el sentimiento religioso; pero es legítimo suponer que los tres argumentos sean colocados en climax y que para él la superstitio haya pesado más.

En una sociedad como la nuestra, de alto nivel industrial, el problema de la contaminación por la imposibilidad de eliminar los deshechos dañinos y por el uso insensato de sustancias químicas - desde los fertilizantes hasta los insecticidas y pesticidas - se pone ya en términos drámaticos. Se podría pensar que el mundo antiguo, por el contrario, no haya advertido nunca el problema de la contaminación de los suelos y de las aguas, y de la polución atmosférica. No parece, en efecto, verosímil que de la agricultura o del pastoreo, de la artesanía o de la limitadísima actividad industrial puedan haber derivado cantitades notables de deshechos: en las zonas metalúrgicas los deshechos de fusión deben haber sido escasos, y por otro lado parece cierto que la elaboración de las pieles no fue causa de contaminación de las aguas, puesto que en ella eran empleados ingredientes vegetales.

Sin embargo un problema debe haber sido puesto por la absorción de los deshechos orgánicos: el sistema cloacal era rudimentario y a veces inexistente aún en las grandes ciudades, a tal punto que no son pocas las alusiones a sus aires no propiamente paradisíacos: Cicerón nos cuenta que Verres, cuando salía en litera, se equipaba sabiamente contra el insoportable hedor gracias a cojines de rosas, a guirnaldas de rosas alrededor del cuello y de la cabeza y a una redecilla de sutilísimo lino, llena ella también de rosas, que acercaba a su nariz. No será arriesgado, por tanto, ver en las deficiencias del sistema cloacal la mayor fuente de contaminación.

Hablar de contaminación atmosférica en el mundo antiguo puede aparecer ridículo en nuestros días, resignados como estamos frente a los humos infectantes de las industrias, a las nubes tóxicas, y hasta al peligro de nubes atómicas. Y la imagen corre de inmediato al confortador et iam summa procul villarum culmina fumant (Verg. Buc. 1,82) como a un cuadro de serena compostura, en que el humo que sale de los caseríos se integra perfectamente al ambiente sin contaminarlo y por el contrario contribuye a hacer más dulce la idea de la puesta del sol. Pero el que Virgilio dibuja es un escenario campestre: en Roma la situación debía ser algo distinta: el humo de tantas chimeneas difícilmente habrá contribuido a la pureza del aire. Nos lo atestigua Séneca, que en una epístola a Lucilio $(104,6)$, describiendo su fuga desde la ciudad hacia la finca nomentana por motivos de salud, afirma que, dejada atrás la atmósfera 
malsana de la ciudad y el olor de las cocinas humeantes - que una vez puestas en función difundían junto con el polvo unas exhalaciones pestilentes - había sentido de inmediato un beneficio para su salud.

Sugestivo, en su brevedad, es un pasaje de Plinio (Nat. 18,2-5) en que son denunciadas con claridad las culpas de los hombres en lo que concierne la contaminación de las aguas y la polución del aire. En el libro XVIII de la Naturalis historia Plinio comienza a hablar de los vegetables que nacen de la tierra benigna: él quiere tomar las defensas de aquella tierra que es madre de todo:

Quoniam tamen ipsa materia accedit intus ad reputationem eiusdem parientis et noxia: nostris eam criminibus urguemus nostramque culpam illi inputamus. Genuit venena, sed quis invenit illa praeter hominem? Cavere ac refugere alitibus ferisque satis est. (...) Nos et sagittas tinguimus ac ferro ipsi nocentius aliquid damus, nos et flumina inficimus et rerum naturae elementa, ipsumque quo vivitur in perniciem vertimus.

"Puesto que, sin embargo, nuestro mismo argumento se extiende hasta la consideración de ella en cuanto generadora de sustancias dañinas, nosotros le imputamos nuestros horrendos crímenes y le endosamos nuestras culpas. Es verdad, ella ha creado los venenos: pero ¿quién ha descubierto la manera de servirse de ellos exceptuando al hombre? Las aves, las fieras se contentan con precaverse de ellos y de rehuirlos. (...) Nosotros, los hombres, envenenamos las flechas y al hierro, por si solo mortal, agregamos algo aún más peligroso. Llegamos hasta envenenar los ríos y los elementos naturales, y el mismo aire que nos es indispensable para vivir terminamos por volverlo irrespirable para nuestra perdición».

Fue, sin embargo, la demolición de bosques y de forestas la que produjo la más vistosas consecuencias en Grecia y en Roma. En Grecia la demolición de forestas estaba ligada a una serie de necesidades primarias: las exigencias de la metalurgia de vastas proporciones, la búsqueda de espacios para el pastoreo, los cultivos, las necesidades de combustible y de madera para la artesanía, la edilicia, los astilleros. El maderaje de la Sila era el más buscado para la edilicia y la construcción de buques, y había variados métodos de explotación: el más empleado consistía en cortar los árboles en su raíz y en hacer avanzar los troncos hacia el puerto más cercano sirviéndose de los ríos o del mar.

Consecuenciainevitable delatala indiscriminada fue un ruinoso desequilibrio idrogeológico, más advertido en Grecia pero no menos evidente en Roma. Los antiguos dieron de él una interpretación que caracteriza en modo elocuente su erónea conciencia del problema: el desequilibrio idrogeológico, en efecto, fue considerado como consecuencia de imprevisibles eventos naturales, mientras no se delimitaron las responsabilidades humanas. En Roma no por casualidad las inundaciones del Tíber comenzaron a hacerse más frecuentes justo en el período en que se hizo más intensa la actividad de tala en el Apenino para hacer frente válidamente a la guerra contra Cartago. Si consideramos los testimonios de los mayores representantes de la cultura, de Lucrecio a Horacio, a Livio, a 
Séneca, podemos verificar cómo el desequilibrio idrogeológico es puesto en relación o con la voluntad de los dioses, o con las catástrofes provocadas por la naturaleza madrastra. Si en algunos casos se esfuerzan de encontrar una razón más plausible de las mencionadas inundaciones, encontrarán amparo en lo irracional y en lo inescrutable.

Es en la relación con el cenagal donde los antiguos han dado probablemente prueba de una competencia mayor que la de los modernos, concibiéndolo en modo diverso que el nuestro. Los cenagales, en nuestro tiempo, se han hecho escasos, eliminados casi en todas partes por obras de saneamiento a veces grandiosas: para el hombre moderno, el cenagal, asociado al peligro de la malaria, es un enemigo al que hay que debelar. Ligado a la idea de decadencia y abandono, el es, de todos modos, considerado un elemento negativo, y sólo en tiempos muy recientes nos hemos dado cuenta, por no citar que un solo ejemplo, del papel insostituible que juegan los grandes pantanos en el equilibrio ecológico del Mediterráneo.

El mundo antiguo había terminado por aceptar los pantanos y por integrarlos a su 'habitat', ya sea por una objetiva incapacidad de concebir audaces obras de saneamientos idráulicos, ya sea por los consabidos temores de sacrilegio. Los hombres podrán ejercer un control sobre el ambiente a cuya creación han contribuido, pero no podrán nunca subvertirlo. Los antiguos, por tanto, no concibieron nunca un proyecto de eliminación de los cenagales sobre la base de un saneamiento integral: si los aceptaron, sin embargo, lo hicieron en determinadas condiciones: el cenagal era aceptado sólo cuando se encontraba marginado de la oikoumene; en cambio, cuando se encontraba perturbando la oikonomia de un territorio, su falta de reglas suscitaba la reacción negativa de los moralistas.

Volvamos, para concluir, al tema general. Más allá de las tomas de posición teóricas, permanecen hoy visibles para todos las consecuencias reales de una relación hombre-ambiente que ha producido modificaciones profundas en el 'habitat' natural: las civilizaciones que se han sucedido unas a otras en la historia de la humanidad no se han limitado a operar inocuas mutaciones en el paisaje ambiental; por el contrario, el hombre se ha hecho culpable del grave estado de degradación en el que actualmente se encuentra el medio ambiente. La inevitable interacción entre hombre y naturaleza ha sido siempre causa de perturbaciones definitivas del ambiente ecólogico, empezando por el agotamiento de algunos recursos naturales. Desde las etapas iniciales, estas perturbaciones han mostrado cómo la actividad del hombre y su misma existencia se expresan en modo singularmente ambivalente: el hombre, por un lado, ha mostrado enormes capacidades de crear y producir para sí un ambiente mejor y mejores condiciones de vida; por el otro, sin embargo, ha dado prueba de su tendencia a destruir aquello que había sido capaz de crear, o a usar sus capacidades precisamente para empeorar el ambiente y las condiciones naturales.

Si en nuestros días tenemos clara conciencia del hecho de que no han sido culpables sólo las sociedades más evolucionadas e industrializadas, sino 
también aquellas llamadas primitivas, no obstante es igualmente claro que la aceleración del desarrollo económico y la enorme ampliación de la producción industrial en los tiempos más recientes, han terminado por poner el problema en términos dramáticos: el exceso incontrolado de productos químicos ha causado un excedente de desperdicios contaminantes y el deterioro de la naturaleza debido a la contaminación del aire, de las aguas, de la tierra, ha alcanzado valores de tal magnitud que ya nos preguntamos sobre la posibilidad misma de duración de la vida en el planeta tierra. Los remedios, por cierto, existen hoy tal como existían en el pasado: el problema es el de aplicarlos. Y si en el pasado era la superstitio la que los hacía inútiles, hoy ellos pasan a través de la vía utópica de un aprovechamento industrial de los recursos más racional y menos ligado a la lógica de la ganancia. Es éste un camino que, en el mundo de hoy, aparece ampliamente comprometido, si hechos recientes nos han mostrado cómo los países más ricos e industrializados tienen la tendencia a tomar a los países pobres y subdesarrollados como receptáculo de los deshechos industriales y de los residuos tóxicos que no logran disolver: como si la oikoumene de los antiguos se agotara hoy dentro de las fronteras del propio país, como si el trasladar a los mares, a las tierras, al aire de otros países sus basuras tóxicas pudiera remover un peligro que atañe, por el contrario, a la tierra en su conjunto.

Pero, será oportuno concluir de modo menos pesimista. Las esperanza nos puede venir, justamente, desde el mundo antiguo, que hasta en sus momentos de mayor pesimismo no abandonó nunca la confianza en una decisiva intervención del hombre para mejorar, junto con el ambiente, sus mismas condiciones de vida. La esperanza, entonces, puede venirnos de un pasaje de Estrabón, en el que el autor teje el elogio de Europa que para él es la tierra ideal pues las favorables condiciones climáticas influyen también sobre la situación política $(2,5,26)$ :

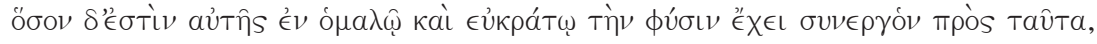

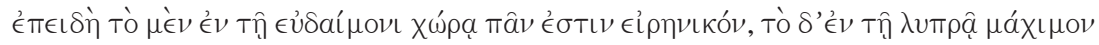

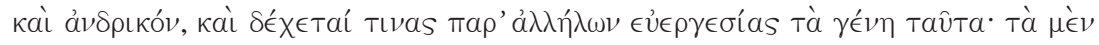

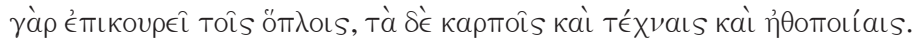

De hecho, como dice Estrabón, «en un país feliz todo concurre para la paz, mientras en un país pobre todo concurre para la guerra y la contienda viril». Sin embargo, continua Estrabón, «los pueblos pueden prestarse ayuda unos a los otros». De los modos que él reseña nosotros rechazaremos, sin

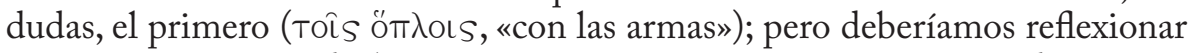
atentamente acerca de los otros, puesto que vivimos en un mundo en que el benestar económico de los pueblos y su poder político van juntos y están ligados a una mayor posibilidad de explotación de los recursos económicos e industriales, aun en detrimento de los pueblos menos ricos y afortunados. Se puede venir al encuentro de estos pueblos, precisamente como dice Estrabón, «con los frutos de la cosecha, con los conocimientos técnicos y con la formación moral». 